sections, and this cutting up of the network required nearly three days. The power was off of parts for all that time. This is one of the dangers to which a large low-tension system is liable and is what the New York Edison Company is striving to avoid by keeping their batteries prepared at all times to assume the total load independent of any generating system.

Mr. Scotr:-I take exception to the broad statement that " the way to maintain continuity of service is to have safety devices "- there may be too many. I know of a large company which installed a great many safety devices and had troubles at various times. After the plant had been running for some four or five years, I made a remark one day to the engineer in charge that most of their troubles had been due to their safety devices. Although the safety device is intended to prevent accidents, it is itself often the very source of accident and of trouble. This is one of the reasons why the fuses have been left out between alternators and bus bars. Fuses, particularly for high voltage or for heavy current, are disagreeable adjuncts to a station equipment. In general it is not good practice to put in a line anything that can be avoided.

Meetirg adjourned.

\title{
Discussion at St. Louis, May 16, 1903.
}

The meeting was called to order at 8.30 P. M., at the Engineers' Club, W. E. Goldsborough, Chairman, presiding.

Announcement was made by Secretary Swope of Mr. Carnegie's gift of $\$ 1,000,000$ to the Associated National Engineering Societies. The Secretary spoke of a local movement for the same object. Mr. Goldsborough made some remarks in regard to the same matter, also in regard to the Institute Building and the better standing it would give to the profession of engineering throughout the country.

Announcement for the next meeting was then made, also for the annual meeting at Niagara.

The papers for the evening were:

No. 1.-" Economical and Safe Limits in Size of Central Stations," read by Mr. Dyer.

No. 2.--" Safety Devices in Central Stations and Substations," read by Mr. Langsdorf.

No. 3.- "Multiple versus Independent Operation of Units and Central Stations," read by Mr. Klauder.

The salient points of the discussion at the New York meeting were read by the Secretary.

The papers were then opened for discussion, in which Mr. E. D. Matlack participated, whose company is now installing a 500 kilowatt General Electric generator, connected to a Curtis turbine. Much discussion was brought out in regard to the question of the advantage of superheating the steam.

Mr. Borden spoke at length on the same subject. 
Mr. Welz, Director of the Word's Fair, told of waste heat engines, which have been largely advanced in Germany, but not, used in this country. He said:

I should like to draw your attention to some new features of modern development of central stations brought out in Germany. When in Berlin last September, I visited the central stations in Markgrafenstrasse where a new type of engine, a so-called "sulphurous anhydride waste-heat engine," was running. The reason for the construction of these machines was the low thermal efficiency of the steam engine which is, in the best machines, only about 23 per cent. The purpose of the waste-heat engine is to use the heat which is generally lost in the exhaust steam for vaporizing a liquid with a low boiling point of which the vapors under the given temperature have already a very high pressure. With these vapors a new engine can be driven. Of all the liquids which can be employed for this process, the sulphurous anhyaride $\left(\mathrm{SO}_{2}\right)$ has proved to be the most practical.

The general scheme of the engines is very simple. The exhaust steam of the steam engine is conducted through a surface condenser which serves as a vaporizer of the $\mathrm{SO}_{2}$ liquid. At a temperature of $150^{\circ} \mathrm{F}$., corresponding to the temperature of steam in an 80 per cent. vacuum, the sulphur dioxide vapors have a pressure of $156.5 \mathrm{lbs}$. per sq. in. abs. These vapors then enter the waste heat engine, which is similar in construction to a steam engine. The sulphur dioxide vapor leaves the engine at a pressure of $4.8 \mathrm{lbs}$. per sq. in. abs. and passes on to a second surface condenser, where, by means of circulating water, it is again liquified. A small pump delivers the liquid sulphur dioxide from the condenser back into the evaporator or the exhaust-steam condenser, where it is ready to repeat the cycle. Hence, neglecting the losses through possible leakage, the working medium is used over and over again and requires no replenishing. The only difficulty in the construction of these machines was to have the stuffing box of the piston-rod tight. After some experiments this difficulty was entirely overcome and Prof. Josse, the constructor of the machines assured me, when I saw him in Berlin, that the machines as now constructed are perfectly satisfactory. The waste-heat engine in the Markgrafenstrasse develops 175 h.p., using the exhaust steam of a 360 h.p. vertical compound steam engine, and thus adds 48.6 per cent. to the energy produced by the steam engine. The cost for such a wasteheat engine is about equal to that of a steam engine of the same size. It is therefore easily seen that in this way the efficiency of electric central stations can be largely increased.

At the present time there are a great number of such wasteheat engines in use or under construction; as an example of the modern construction of these machines, I can show you a picture of a 200 h.p. and a 450 h.p. waste-heat engine. the first built by the Maschinenfabrik Sulzer the latter by the Goerlitzer Maschinenbauanstalt. The waste-heat engines for the utilization of 
exhaust steam are now entirely worked out as turbines as well as piston engines. Trials have been made lately for the utilization of flue gases of boilers, blast furnace gases, exhaust gas of gasengines, etc., and these trials give satisfactory results, but the company which exploits these patents is not yet ready to put the machines on the market.

I should like to show you a very interesting diagram; you see here upon the upper side of the drawing the general disposition of a steam plant: boiler, steam engine and waste-heat engine; the diagram below shows in per cent. of the heat energy produced in the boiler the amount of energy developed in the steam engine and in the waste-heat engine and the losses which occur during this process. According to this, 12 per cent. of the original heat is utilized in the steam engine and 4 per cent. in the waste-heat engine; 2 per cent. is lost in the ashes, 7 per cent. by radiation from the boiler, 22 per cent. goes in the flue gases, where 6 per cent. is recovered by the economizer and 16 per cent. escapes through the chimney, 2 per cent. is lost in the piping from the boiler to the steam engine, 2 per cent. radiated from the steam engine, $1 \frac{1}{2}$ per cent. in the steam piping to the vaporizer and $53 \frac{1}{2}$ per cent. is lost in the cooling water.

\section{Discussion at Philadelphia, May $11,1903$.}

Chatrman Hering:- The papers are now open for general discussion.

Mr. Wm. C. L. EGLIN:-There are one or two points on which I differ with Mr. Torchio, particularly on the question of opening both the oil-switches in series. It seems to me it would be much better to open first one switch and if that fails open the second, for the reason that the arc introduced by the failure of the first switch will very materially reduce the load to be opened by the second switch. It is possible, in opening both together, that both might explode and form an arc which, of course, could not be put out under many conditions without shutting down the generator.

Mr. Lardner speaks of large versus small stations. I cannot agree in any way with the author of this paper in connection with stations for light and power. In the first place the location of the central station is perhaps the most important single feature of the system. A desirable or a perfect location is 